\title{
El nuevo Derecho Procesal del trabajo en México
}

\author{
Josefa Montalvo Romero*
}

\section{Martínez Martínez, Jorge y Pérez Estrada Laura Celia, (2019), Derecho Procesal del Trabajo, OXFORD, México.}

Vivimos en una época de cambios y transformación del conocimiento, que propician la aparición de nuevas realidades jurídicas que implican replantearse la formación jurídica bajo nuevos paradigmas, obligándonos a estar preparados para su interpretación y comprensión. El libro que se comenta nos inspira a ello y nos lanza en esta aventura que significa la enseñanza del derecho.

Producto de la reforma Constitucional del año 2017 y Legal del 1 de mayo del 2019, el Derecho Procesal del Trabajo en nuestro país toma características totalmente innovadoras en las que se ha transformado la impartición de justicia laboral.

Como estudiosos del derecho y formadores en las aulas universitarias agradecemos las metodologías y didácticas que los autores logran en la obra y que facilitan no solo el "que enseñar" sino también el "cómo enseñar", dejando en el pasado una enseñanza jurídica discursiva, memorística y repetitiva que omite todo juicio crítico y participativo de estudiantes pasivos y esencialmente receptivos (Witker, 2008: 944).

En este sentido, es de resaltar que la estructura del libro logra dotar al estudiante de orientaciones didácticas generales para cada tema, de tal suerte que pueda alcanzar los aprendizajes esperados de forma autónoma.

Por otra parte, los contenidos desarrollados resultan fundamentales para el ejercicio profesional, pues dotan al mercado mexicano de abogados con conocimientos sólidos en el Derecho Procesal del Trabajo, que contribuyen a la mejora y profesionalización del ejercicio de esta rama jurídica.

De forma por demás acertada, los autores señalan que:

...para poder dar adecuada solución a los conflictos de trabajo se requiere la comprensión de las instituciones jurídicas, de los conceptos y relaciones que establecen entre si y de las normas de trabajo a partir de la ley de la materia, pero también considerando la norma fundamental, la interpretación que hace el poder judicial de la federación, las normas supranacionales y las de naturaleza contractual (2019: 7).

\footnotetext{
* Investigadora de Tiempo Completo del Centro de estudios sobre Derecho, Globalización y Seguridad de la Universidad Veracruzana.
} 
Con este contexto, el primer apartado nos presenta aspectos generales del derecho procesal del trabajo, pues como bien lo señalan los autores en la introducción, pretende ser una guía para los alumnos que tienen su primer acercamiento con la materia. Los capítulos dos y tres se dedican a las notificaciones, exhortos, términos procesales e incidentes siguiendo con el estudio de las pruebas. Los siguientes tres capítulos dan cuenta del proceso ordinario laboral, procesos especiales y conflictos colectivos de naturaleza económica. Los temas de sindicatos y huelga abarcan los capítulos siete, ocho y nueve.

De manera pertinente en los capítulos posteriores se exponen tres temas que nos parecen indispensables en el estudio del derecho del trabajo; las reformas constitucionales en materia de justicia laboral, el derecho procesal del trabajo burocrático y el derecho internacional del trabajo.

El impacto que la desaparición de las Juntas de Conciliación y Arbitraje representa en la impartición de justicia laboral no es menor. El 24 de febrero del 2017 se sentaron las bases para un nuevo sistema de justicia laboral bajo dos esquemas: La solución de los conflictos por tribunales federales y locales, y la obligación de las partes (trabajadores y patrones) de asistir a la instancia conciliadora antes de acudir a los tribunales. No olvidemos que desde 1917 en que se promulgó nuestra Constitución, la fracción XX del artículo 123 había permanecido intocable estableciendo la competencia de la Juntas de Conciliación y Arbitraje fedérales y locales.

Por otro lado, el éxito de la instancia conciliadora previa dependerá de insistir en una nueva cultura laboral, donde la conciliación sea la parte medular, en el entendido de que una cosa es conciliar efectivamente los intereses y otra muy distinta asistir solo por obligación a la instancia.

Conscientes de que el mundo del trabajo no es estático, sino dinámico, es indispensable el análisis, que a partir de las reformas laborales, se haga sobre el nuevo rol de las organizaciones sindicales, sabemos que durante mucho tiempo los sindicatos de todo el mundo por ejemplo, han lidiado con el impacto de la sustitución de la mano de obra por la tecnología. Existen medidas muy conocidas que garantizan su implementación productiva y minimizan los impactos negativos. Las medidas pueden desarrollarse en el marco de negociaciones tripartitas, en las que los trabajadores tienen el derecho a consulta, compensación y capacitación. Cuanto mayor sea la sujeción de una economía al control social, menor será el impacto negativo de la tecnología, simplemente porque los factores externos son tenidos en cuenta antes de su adopción (Figueroa, 2019: 51). ${ }^{1}$

Por su parte el derecho internacional del trabajo garantiza la efectividad de derechos laborales previstos en normas internacionales o nacionales, en específico los contenidos en los convenios 87 y 98 de la OIT, dependen en gran medida de la existencia de un sindicalismo legítimo, representativo y con los recursos de poder necesarios para lograr su pleno respeto. Por eso, en la práctica, el pleno ejercicio de la libertad sindical y la negociación colectiva tiene una importancia mayor que cualquier otro derecho laboral

\footnotetext{
${ }^{1}$ Figueroa, V. ¿Hacia el fin del trabajo? Mitos, verdades y Especulaciones, Revista Nueva Sociedad No 279, enero-febrero de 2019, p.51. www.nuso.org
} 
fundamental, e incluso se ha creado un órgano y un procedimiento especial de monitoreo en el marco de la OIT a cargo del Comité de Libertad Sindical.

Finalmente el éxito o no de las reformas laborales es todavía incierto, mientras tanto recomiendo ampliamente la lectura del libro cuyo valor agregado es su carácter didáctico convirtiéndolo en una herramienta innovadora y pertinente para entender el mundo del trabajo hoy.

\section{Fuentes consultadas}

Figueroa, V. (2019). “¿Hacia el fin del trabajo? Mitos, verdades y Especulaciones”, Revista Nueva Sociedad, No 279, enero-febrero de 2019. Disponible en: www.nuso.org

Witker, J. (2008). "Hacia una investigación jurídica integrativa", Boletín Mexicano de Derecho Comparado, año XLI, núm. 122, p. 944, IIJ-UNAM. 